\title{
PROCESSO DE COLONIZAÇÃO DO MANGUEZAL DO RIO TAVARES POR ANÁLISE DA ESTRUTURA DE DIFERENTES BOSQUES
}

\author{
OLIVEIRA, R.G.* \& TOGNELLA, M.M.P. ${ }^{1}$ \\ 1 - Universidade Federal do Espírito Santo \\ *Corresponding author: rafaela_go@hotmail.com
}

\begin{abstract}
Oliveira, R.G. \& Tognella, M.M.P. (2014) Processo de colonização do manguezal do rio Tavares por análise da estrutura de diferentes bosques. Braz. J. Aquat. Sci. Technol. 18(1): 9-18. eISSN 1983-9057. DOI: 10.14210/bjast. v18n1.p9-18 Mangrove forests physiography was studied to understand the colonization process. Two transversals were made perpendicular to the Tavares River and twelve plots were established along an inundation flux. The quadrats were delimited and took structural data was collectd on specimens density, tree stature and diameter breast height. Avicennia schaueriana was the dominant species and Rhizophora mangle and Laguncularia racemosa were registries. Nine quadrats was dominated by $A$. schaueriana, two of them showed $R$. mangle and one, $L$. racemosa. $A$. schaueriana is the most adapted species, dominating in basal area and it is the first species to colonize the plots. Our structural data give us some classification of the stand colonization, being able to differentiate forest in colonization, development and mature stages.
\end{abstract}

Keywords: colonization, mangrove structure, mangrove forests.

\section{INTRODUÇÃO}

Manguezal é um ecossistema que ocorre em regiões tropicais e sub-tropicais ocupando áreas entremarés. É caracterizado por vegetação lenhosa típica, adaptada às condições de maré, salinidade, substrato inconsolidado e pouco oxigenado. Uma fauna típica compõe ainda esse ecossistema, igualmente adaptada as características peculiares do ambiente (Soares, 1997).

A fisionomia e formação da vegetação dos manguezais parecem ser fortemente controladas por padrões locais relacionados à maré e à drenagem da superfície terrestre. Por isso, Lugo \& Snedaker (1974) classificam esta comunidade vegetal de acordo com topografia e influência da maré na distribuição das espécies típicas e das unidades fisionômicas. Segundo este sistema de classificação, os bosques de mangue podem ser: (1) Bosques ribeirinhos; (2) Bosques de franja e ilhota; e (3) Bosques de bacia.

Uma característica marcante dos manguezais é a existência, em alguns bosques, de zonas ou faixas distintas, compostas por apenas uma espécie ou por um dado conjunto de espécies arbóreas. Dá-se o nome de zonação a distribuição dos organismos em áreas, camadas ou zonas distintas. Podem-se apresentar dois tipos de zonação: vertical e horizontal, e esta se divide em zona externa, interna, apicum e transição (Lugo \& Snedaker, 1974; Cintrón \& Schaeffer-Novelli, 1983; Schaeffer-Novelli et al., 2001). Para Lugo (1987 apud Sessegolo, 1997), as zonações obedecem a gradientes ambientais de salinidade, topografia e hidrologia, entre outros, enquanto que as sucessões são fenômenos temporais. Segundo Snedaker (1982), a zonação no manguezal é uma expressão da sucessão vegetal, uma resposta a mudanças geomorfológicas e fisiológicas, e aos gradientes de marés, além de uma consequência da dispersão preferencial de propágulos. O processo de desenvolvimento estrutural de um bosque pode ser descrito segundo modelo proposto por Jimenéz et al. (1985), e consiste nas seguintes etapas: (1) Período de colonização; (2) Período de desenvolvimento; (3) Período de maturidade; e (4) Senescência.

Os bosques de mangue apresentam grande variabilidade, ao longo do litoral catarinense, em relação as suas características estruturais e funcionais. No litoral catarinense são encontradas três das seis espécies típicas de mangue, que ocorrem no Brasil: Rhizophora mangle (mangue vermelho), Laguncularia racemosa (mangue branco) e Avicennia schaueriana Stapf and Leechman ex Moldenke (mangue preto), além de algumas espécies associadas.

Santa Catarina é o Estado limítrofe de distribuição do ecossistema manguezal no Brasil, e possui poucas regiões onde o mesmo é bastante expressivo como, por exemplo, Baía da Babitonga (São Francisco do Sul e Joinville) e a llha de Santa Catarina, sendo muitas vezes substituído por vegetação de marisma. O município Laguna é o limite austral dos manguezais no continente americano.

Em outras regiões estuarinas do estado existem bosques com menor expressividade em termos de extensão, mas bastante importantes na contribuição da qualidade ambiental costeira, como aqueles manguezais localizados nas cidades de Barra Velha, Piçarras/Penha, Penha/Navegantes, Itajaí, Balneário Camboriú, Itapema, Bombinhas, Laguna, entre outros.

A avaliação dos parâmetros estruturais é fundamental para o acompanhamento em longo prazo 
dos processos ecológicos que ocorrem em florestas como, por exemplo, processos de sucessão de espécies. O principal objetivo deste estudo é averiguar o processo de colonização do manguezal do Rio Tavares avaliando a estrutura e a composição de espécies em diferentes bosques, podendo contribuir com a produção de dados e embasamento teórico para os estudos ecológicos do manguezal do Rio Tavares e suas respostas às mudanças ambientais naturais ou induzidas pelo homem, nas diversas escalas temporais.

\section{MATERIAIS E MÉTODOS}

O presente estudo foi realizado no manguezal do Rio Tavares localizado na Baía Sul (Figura 1), ao sul da zona central do Município de Florianópolis (Ilha de Santa Catarina). O manguezal estudado situa-se na bacia hidrográfica do Rio Tavares, que é a segunda maior da ilha em superfície, composta principalmente por dois cursos d'água localizados quase inteiramente na região oeste: o Rio Tavares (com aproximadamente $7 \mathrm{Km}$ de extensão, com poucos e estreitos afluentes e desaguando na Baía Sul) e o Ribeirão da Fazenda, que se une ao Rio Tavares (Caruso, 1983).

Para escolha das parcelas foram analisadas fotografias aéreas da região, referentes obtidas em novembro de 2001, sendo determinadas as áreas onde seria possível avaliar o processo de colonização do bosque e onde não ocorresse a presença de clareiras.

Neste estudo foram realizadas 12 parcelas no manguezal do Rio Tavares, sendo que na margem esquerda foram posicionadas as parcelas I, II, III, IV e $\mathrm{V}$, situadas perpendicularmente ao canal do rio ao longo de um canal de maré, sendo denominadas do continente para a margem do rio. Na margem direta foram distribuídas perpendicularmente à margem as parcelas VI, VIII e IX, nomeadas da borda do rio para o continente, e foram distribuídas paralelamente à margem as demais (VII, X, XI e XII) (Figura 2). Destaca-se a ocorrência das três espécies existentes para o sudeste-sul do Brasil, A. schaueriana, $L$. racemosa e $R$. mangle, em diferentes composições estruturais. Foram obtidos dados de posicionamento para cada parcela amostrada com GPS Garmin.

A coleta de dados foi realizada de maio a outubro de 2004 e de março a maio de 2005. A metodologia de amostragem é baseada em Schaeffer-Novelli \& Cintrón (1986). Cada parcela tem tamanho de 20×20m, contendo no mínimo 30 a 40 indivíduos, cuja altura seja superior a $1,3 \mathrm{~m}$, conforme metodologia citada acima.

Foram observados os seguintes parâmetros para cada espécie: número de indivíduos e de troncos (vivos e mortos), diâmetro $(\mathrm{cm})$, altura $(\mathrm{m})$ e presença de propágulos e plântulas. A altura foi estimada com telêmetro óptico e o diâmetro foi obtido diretamente, empregando-se trena calibrada em $\pi$. Em laboratório, esses dados foram trabalhados e transformados em densidade absoluta (convertida para indivíduos por hectare) e relativa e dominância por classe de diâmetro, por espécie, para troncos e indivíduos. Cada um destes parâmetros serve como indicativo da estrutura e do funcionamento do bosque, pois determinando a maturidade, a espécie predominante e o grau de preservação do mesmo, pode-se avaliar como está ocorrendo o processo de ocupação desse ecossistema.

Diferentemente do proposto pela literatura (Schaeffer-Novelli \& Cintrón 1986), os dados de estrutura foram avaliados em classes de diâmetro em intervalos de $2,5 \mathrm{~cm}$ entre elas. Esta divisão foi proposta como método para avaliar os processos de colonização entre as parcelas.

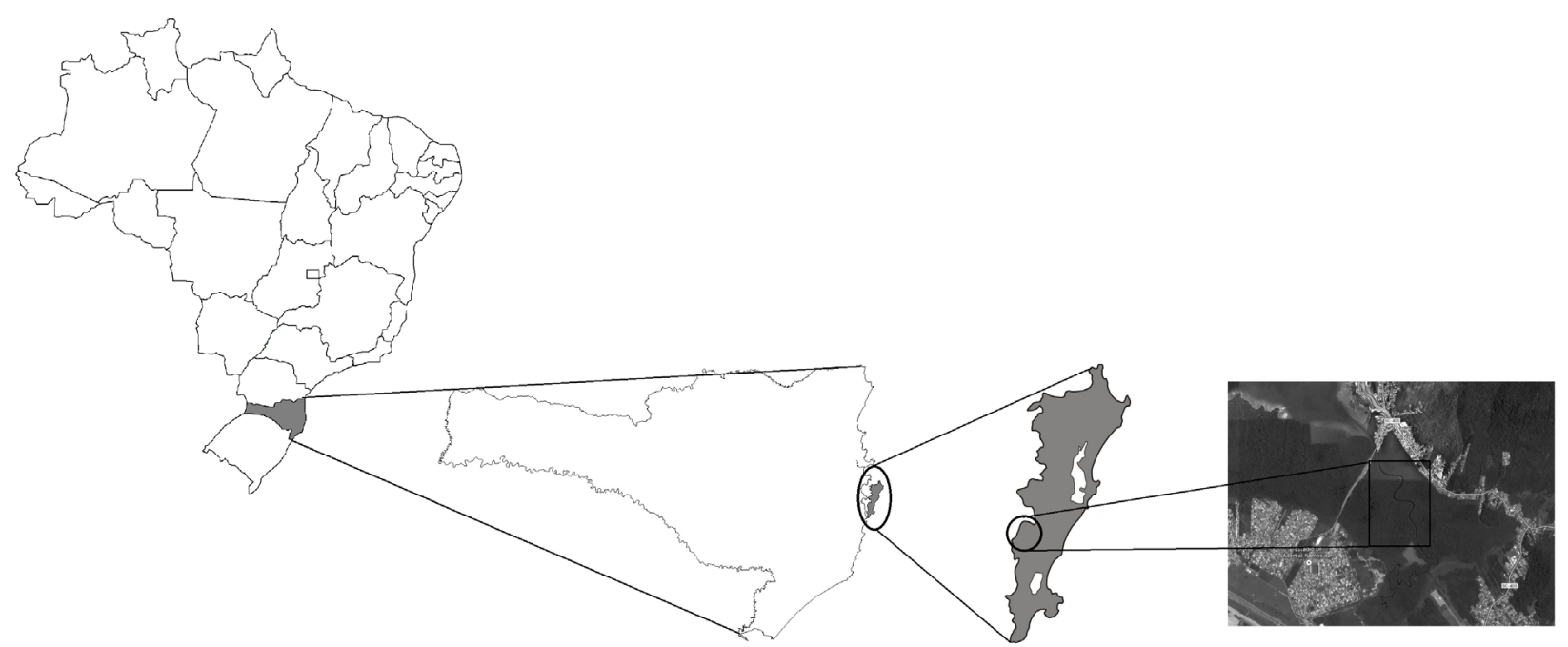

Figura 1 - Localização esquemática do manguezal do Rio Tavares (Florianópolis, SC), destacando a área de estudo. 


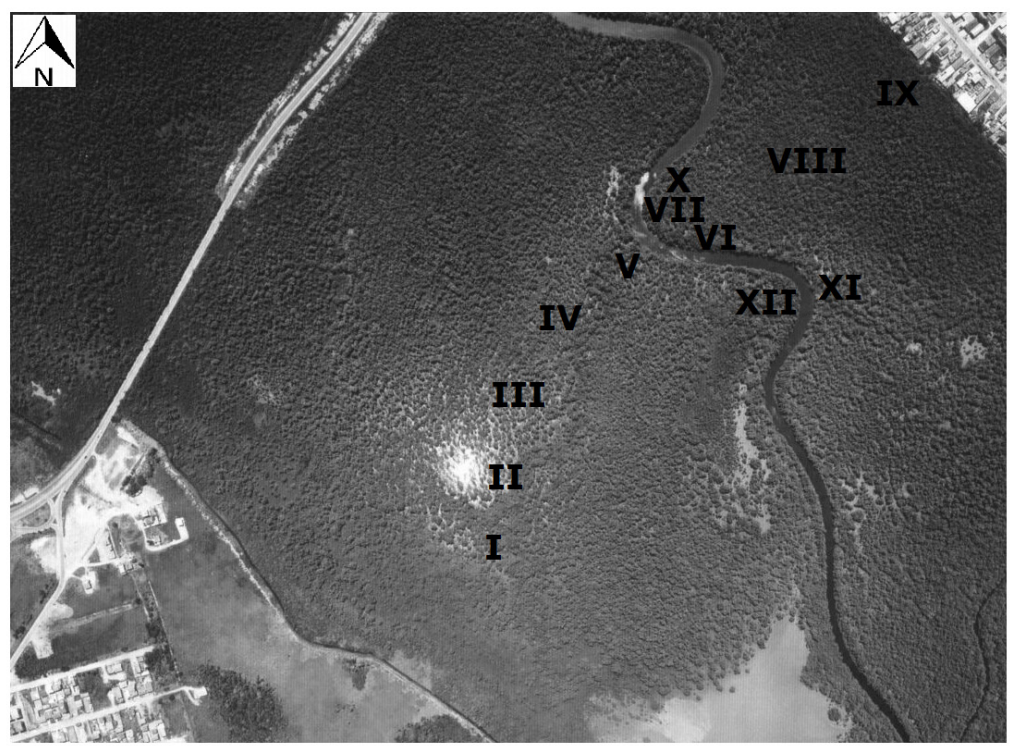

Figura 2 - Localização esquemática das parcelas na área de estudo (IPUF, 2001, escala 1:8.000), sendo o curso de água central o Canal do Rio Tavares.

Para diferenciar os indivíduos mortos entre mortalidade natural e induzida pelo homem, em campo, foram realizadas observações do tipo de morte do indivíduo. Estes dados foram utilizados para a interpretação dos processos de colonização das parcelas.

\section{RESULTADOS E DISCUSSÃO}

Analisando os dados de estrutura, a parcela I (Tabela I), localizada no interior do manguezal (Figura 2), apresentou o menor DAP médio, o que resultou na maior densidade de indivíduos entre todas as parcelas, destacando-se $R$. mangle com $68,9 \%$ dos indivíduos (Tabela II) e A. schaueriana dominando em área basal. A parcela IX, também no interior do bosque, mas na margem oposta do rio em relação à parcela I, registrou a menor densidade de indivíduos (Tabela I) dominando $A$. schaueriana tanto em área basal quanto em densidade de indivíduos (Tabela II).
A parcela $\mathrm{XI}$, na margem direita do rio, apresentou a menor área basal total $\left(10,28 \mathrm{~m}^{2} / \mathrm{ha}\right)$. A parcela XII, na margem esquerda rio na mesma direção da parcela $\mathrm{XI}$, registrou o maior DAP médio $(12,4 \mathrm{~cm})$ e o maior índice de área basal total $\left(31,63 \mathrm{~m}^{2} / \mathrm{ha}\right)$, sendo que $A$. schaueriana domina em área basal e em densidade de indivíduos.

A proporção de troncos por indivíduos mantevese próxima a 1 em todas as parcelas, sendo indicativo de um baixo estresse ambiental como, por exemplo, variação de salinidade ou condições de anoxia que drenam energia do indivíduo e, consequentemente, aumentam o número de troncos para cada indivíduo. Bosques bem desenvolvidos, crescendo sob condições adequadas, têm uma relação de troncos por indivíduo próximo a 1 e sob condições menos favoráveis aumentam o número de ramificações por indivíduos (Shaeffer Novelli \& Citrón, 1986).

$\mathrm{Na}$ parcela XI, situada na margem direita do rio, A. schaueriana apresenta domínio em área

Tabela 1 - Caracterização estrutural das parcelas.

\begin{tabular}{ccccc}
\hline \hline Parcela & $\begin{array}{c}\text { Densidade } \\
\left(\mathrm{n}^{\circ} \text { indiv/ha }\right)\end{array}$ & $\begin{array}{c}\text { DAP médio } \\
(\mathrm{cm})\end{array}$ & $\begin{array}{c}\text { Área basal } \\
\text { total }\left(\mathrm{m}^{2} / \mathrm{ha}\right)\end{array}$ & $\begin{array}{c}\text { Proporção } \\
\text { troncos/indiv }\end{array}$ \\
\hline I & 3375 & 6,8 & 13,53 & 1,11 \\
II & 2875 & 6,9 & 11,88 & 1,10 \\
III & 1775 & 8,7 & 11,58 & 1,10 \\
IV & 1800 & 10,5 & 17,51 & 1,13 \\
V & 2450 & 7,6 & 12,41 & 1,10 \\
VI & 2225 & 10,3 & 23,33 & 1,26 \\
VII & 1800 & 8,7 & 13,88 & 1,29 \\
VIII & 1625 & 10,6 & 18,03 & 1,26 \\
IX & 1175 & 9,7 & 10,68 & 1,23 \\
X & 2425 & 8,9 & 18,36 & 1,22 \\
XI & 2175 & 7,4 & 10,28 & 1,10 \\
XII & 2250 & 12,4 & 31,63 & 1,17 \\
\hline \hline
\end{tabular}


basal $\left(5,45 \mathrm{~m}^{2} / \mathrm{ha}\right), L$. racemosa, em dominância de indivíduos $(55,17 \%)$ e $R$. mangle ocorre de forma menos representativa (Tabela III). Nas parcelas I e II, conforme pode ser observado na Tabela III, o domínio em número de indivíduos é registrado para $\mathrm{R}$. mangle com 68,89 e 40,87\%, respectivamente.

Conforme pode ser observado na Tabela II, $A$. schaueriana apresentou os maiores valores de área basal viva em todas as parcelas e dominou em número de indivíduos em $75 \%$ das parcelas.

Na parcela XII há ocorrência de $A$. schaueriana e $L$. racemosa, sendo esta representada por menos de $1 \%$ de dominância de indivíduos com uma área basal total de $0,07 \mathrm{~m}^{2} /$ ha (Tabela II). Embora essa parcela esteja localizada na margem do rio, não há presença de $R$. mangle. Em geral, na distribuição horizontal do manguezal, a espécie dominante é comumente $R$.

Tabela 2 - Dados de área basal e porcentagem de indivíduos por espécie, onde: Lg: Laguncularia racemosa, Av: Avicennia schaueriana e Rz: Rhizophora mangle..

\begin{tabular}{|c|c|c|c|c|c|}
\hline \multirow{2}{*}{ Parcela } & \multirow{2}{*}{ Espécie } & \multicolumn{2}{|c|}{ Área basal $\left(\mathrm{m}^{2} / \mathrm{ha}\right)$} & \multicolumn{2}{|c|}{$\%$ indivíduos } \\
\hline & & viva & morta & vivo & morto \\
\hline \multirow{3}{*}{1} & $\mathrm{Lg}$ & 0,83 & 0,08 & 6,67 & 0,00 \\
\hline & $A v$ & 8,13 & 0,40 & 19,26 & 1,48 \\
\hline & $\mathrm{Rz}$ & 3,95 & 0,15 & 68,89 & 3,70 \\
\hline \multirow{3}{*}{ II } & $\mathrm{Lg}$ & 2,10 & 0,40 & 16,52 & 6,96 \\
\hline & $A v$ & 6,80 & 0,03 & 26,96 & 0,00 \\
\hline & $\mathrm{Rz}$ & 2,28 & 0,28 & 40,87 & 8,70 \\
\hline \multirow{3}{*}{ III } & $\mathrm{Lg}$ & 0,70 & 0,15 & 12,68 & 2,82 \\
\hline & $A v$ & 9,65 & 0,23 & 53,52 & 4,23 \\
\hline & $\mathrm{Rz}$ & 0,58 & 0,28 & 18,31 & 8,45 \\
\hline \multirow{3}{*}{ IV } & $\mathrm{Lg}$ & 0,50 & 0,00 & 13,88 & 0,00 \\
\hline & $A v$ & 14,83 & 1,32 & 55,55 & 23,61 \\
\hline & $\mathrm{Rz}$ & 0,63 & 0,23 & 4,17 & 2,78 \\
\hline \multirow{3}{*}{ V } & $\mathrm{Lg}$ & 0,80 & 0,10 & 9,18 & 0,00 \\
\hline & $A v$ & 10,50 & 0,35 & 72,44 & 7,14 \\
\hline & $\mathrm{Rz}$ & 0,55 & 0,13 & 10,20 & 1,02 \\
\hline \multirow{3}{*}{ VI } & $\mathrm{Lg}$ & 1,83 & 0,82 & 20,22 & 12,35 \\
\hline & $A v$ & 18,27 & 0,07 & 55,05 & 1,12 \\
\hline & $\mathrm{Rz}$ & 2,32 & 0,00 & 11,23 & 0,00 \\
\hline \multirow{3}{*}{ VII } & $\mathrm{Lg}$ & 0,60 & 0,07 & 13,88 & 1,39 \\
\hline & $A v$ & 9,93 & 0,20 & 50,00 & 0,00 \\
\hline & Rz & 2,95 & 0,16 & 31,94 & 2,77 \\
\hline \multirow{3}{*}{ VIII } & $\mathrm{Lg}$ & 0,08 & 0,00 & 7,69 & 0,00 \\
\hline & $A v$ & 17,64 & 0,13 & 83,08 & 1,54 \\
\hline & $\mathrm{Rz}$ & 0,17 & 0,00 & 7,69 & 0,00 \\
\hline \multirow{3}{*}{ IX } & $\mathrm{Lg}$ & 0,018 & 0,00 & 2,17 & 0,00 \\
\hline & $A v$ & 9,75 & 0,13 & 71,74 & 8,70 \\
\hline & $\mathrm{Rz}$ & 0,77 & 0,00 & 17,39 & 0,00 \\
\hline \multirow{3}{*}{$X$} & $\mathrm{Lg}$ & 1,19 & 0,20 & 25,77 & 2,06 \\
\hline & $A v$ & 11,47 & 4,56 & 53,60 & 7,21 \\
\hline & $\mathrm{Rz}$ & 0,89 & 0,07 & 10,30 & 1,03 \\
\hline \multirow{3}{*}{ XI } & $\mathrm{Lg}$ & 3,85 & 0,16 & 55,17 & 3,44 \\
\hline & $A v$ & 5,45 & 0,04 & 32,18 & 0,00 \\
\hline & $\mathrm{Rz}$ & 0,78 & 0,00 & 9,19 & 0,00 \\
\hline \multirow{3}{*}{ XII } & $\mathrm{Lg}$ & 0,07 & 0,00 & 0,22 & 0,00 \\
\hline & $A v$ & 31,52 & 0,04 & 99,65 & 0,13 \\
\hline & $\mathrm{Rz}$ & 0,00 & 0,00 & 0,00 & 0,00 \\
\hline
\end{tabular}

mangle (Lugo \& Snedaker, 1974; Cintrón \& SchaefferNovelli, 1983; Schaeffer-Novelli et al., 2001), mas isso não acontece neste ponto, onde há dominância de $A$. schaueriana, tanto em área basal quanto em densidade de indivíduos, respectivamente, com $31,52 \mathrm{~m}^{2} /$ ha e 99,65\% (Tabela II). Estas observações indicam que a zonação e a disposição das espécies ao longo de um gradiente é variável de um bosque para outro, devido suas peculiaridades ambientais.

$\mathrm{Na}$ análise da altura média por espécie (Tabela III), A. schaueriana apresentou a maior altura média, com exceção das parcelas VI e VII, nas quais a $R$. mangle apresentou os maiores valores. Já em relação à altura média total, destaca-se a parcela XII com a presença de árvores mais altas e também com maior desvio padrão entre as observações.

Analisando as curvas referentes às distribuições de frequência de indivíduos por classe de diâmetro para cada parcela (Figura 3), pode-se concluir que as parcelas I e V apresentam tipo de distribuição em forma de $\mathrm{J}$ invertido, onde há predomínio de indivíduos nos intervalos de diâmetro 2,6-5,0 cm e 5,1-7,5 cm, respectivamente. Este tipo de curva de distribuição de indivíduos indica um processo de mortalidade natural, causado por competição devido à maior densidade de mortos nas classes inferiores, associada a processo de amadurecimento do bosque, que apresenta alta probabilidade de se sustentar devido à disponibilidade de indivíduos jovens (Soares et al., 2003). Porém, no caso dessas parcelas há uma baixa dominância de indivíduos mortos, sendo representada por 5,19 e $8,16 \%$, respectivamente, do total de indivíduos. Isso pode representar o ingresso recente de indivíduos na área sem estar ocorrendo ainda o processo de competição que induziria uma alta mortalidade de juvenis.

Em relação à parcela I e analisando os resultados da interpretação das fotografias aéreas realizadas por Lugli (2004), pode-se afirmar que esta parcela representa um processo de colonização recente, iniciada a partir do ano de 1994.

As parcelas IV e IX possuem distribuição de indivíduos mais homogênea, com densidades próximas em quase todas as classes de diâmetro. Proporcionalmente, na parcela IV há tanto indivíduos vivos quanto mortos para as classes de DAP entre 2,6-7,5 cm, mas os indivíduos mortos são na maioria devido ao corte de árvores de $A$. schaueriana, que representa cerca de $20,8 \%$ do total de indivíduos dessa parcela, causando um impacto acentuado na estrutura do bosque.

As parcelas II, III, VI, VII, X e XI apresentam curvas normais de distribuição de frequência. Nas parcelas II e III, os indivíduos estão concentrados principalmente nas classes entre $2,6-5,0 \mathrm{~cm}$ e 5,1$7,5 \mathrm{~cm}$. Na parcela $\mathrm{VI}$, as classes representativas de 
Tabela 3 - Altura média $(\mathrm{m})$ das espécies, altura total média e desvios padrões, e altura do dossel, onde: Lg: L. racemosa, Av: A. schaueriana e Rz: R. mangle.

\begin{tabular}{|c|c|c|c|c|c|c|c|c|c|}
\hline \multirow{2}{*}{ Parcela } & \multicolumn{2}{|r|}{$\mathrm{Lg}$} & \multicolumn{2}{|r|}{ Av } & \multicolumn{2}{|c|}{$\mathrm{Rz}$} & \multicolumn{2}{|c|}{ Total $(\mathrm{m})$} & \multirow{2}{*}{ Dossel } \\
\hline & Média & DesvPadr & Média & DesvPadr & Média & DesvPadr & Média & DesvPadr & \\
\hline $\mathrm{I}$ & 3,7 & 1,52 & 8,0 & 3,82 & 3,6 & 1,21 & 4,5 & 2,66 & 12,7 \\
\hline II & 5,0 & 1,82 & 6,8 & 3,48 & 4,0 & 1,35 & 5,1 & 2,60 & 11,0 \\
\hline III & 4,2 & 1,18 & 6,9 & 4,27 & 3,1 & 1,39 & 5,6 & 3,82 & 13,3 \\
\hline IV & 2,4 & 0,90 & 7,1 & 2,75 & 5,5 & 1,50 & 6,2 & 3,03 & 11,0 \\
\hline V & 3,0 & 0,96 & 5,6 & 2,98 & 4,1 & 1,47 & 5,2 & 2,84 & 11,0 \\
\hline VI & 4,6 & 2,68 & 7,5 & 4,39 & 8,8 & 3,20 & 6,9 & 4,10 & 15,5 \\
\hline VII & 3,0 & 0,90 & 5,7 & 3,87 & 6,2 & 2,04 & 5,5 & 3,28 & 12,3 \\
\hline VIII & 2,0 & 0,32 & 7,4 & 3,52 & 3,2 & 2,47 & 6,7 & 3,74 & 13,3 \\
\hline IX & 2,5 & 0,00 & 7,4 & 3,07 & 6,2 & 3,47 & 7,0 & 3,19 & 11,0 \\
\hline$x$ & 2,6 & 0,65 & 4,8 & 2,79 & 3,5 & 2,09 & 4,0 & 2,50 & 9,2 \\
\hline$X I$ & 3,2 & 1,48 & 5,1 & 2,74 & 3,8 & 1,39 & 3,9 & 2,16 & 9,2 \\
\hline XII & 2,5 & 1,41 & 7,9 & 4,85 & 0,0 & 0,00 & 7,8 & 4,86 & 16,1 \\
\hline
\end{tabular}

indivíduos vivos e mortos situam-se entre 2,6-5,0 $\mathrm{cm}$ e $5,1-7,5 \mathrm{~cm}$, mas os indivíduos mortos estão em menor quantidade, representando $13,5 \%$ do total de indivíduos. Na VII há predomínio de indivíduos na classe de DAP 5,1-7,5 cm. E, nas parcelas X e XI, a maior densidade de indivíduos está entre as classes de DAP de 2,6-5,0 cm e 5,1-7,5 cm. Nesse tipo de curva de distribuição, o bosque caracteriza-se como sendo relativamente homogêneo. Neste caso, o domínio de indivíduos ocorre nas classes de diâmetro médio; os mortos apresentam-se nas classes intermediárias, indicando bosques saudáveis, cuja mortalidade é um processo natural de amadurecimento do bosque e recrutamento de novos indivíduos, mesmo que esporádico, e os jovens depois de um tempo morrem por competição (Soares et al., 2003). Das parcelas que apresentam este tipo de curva, em geral, todas continham indivíduos nas classes extremas de diâmetro.

As parcelas VIII e XII apresentam um tipo de curva que definimos como bimodal, onde na parcela VIII há predominantemente indivíduos vivos $(98,5 \%$ de dominância na parcela) nas classes entre 5,1-7,5 cm e 15,1-17,5 cm, principalmente; e na XII, nas três primeiras classes de DAP (que corresponde de $0,1 \mathrm{~cm}$ até $7,5 \mathrm{~cm}$ ) e, posteriormente, entre $20,1-35,0 \mathrm{~cm}$ de diâmetro.

Lugli (2004) utilizou fotografias aéreas para interpretações sobre uma clareira deste manguezal em estudo, empregando o princípio da esteroscopia para determinar os diferentes padrões da vegetação, para isto baseou-se em diferentes texturas, tons de cinza e altura que pudessem indicar processo de ocupação dos bosques de mangue. As parcelas VIII e IX localizam-se no interior do bosque na margem direita do rio, em uma área que segundo esta autora possui características de vegetação de alto porte, com densidade média, representando bosques de mangue maduros dominados pela espécie $A$. schaueriana.
As parcelas III, IV e V, localizadas ao longo da gâmboa na margem esquerda do rio, e as parcelas VI, VII, X, XI e XII dispostas na margem do Rio Tavares, também possuem características similares às descritas por Lugli (2004), correspondendo também a bosques maduros. Entretanto, para a parcela XI obteve-se dominância de $L$. racemosa em densidade (Tabela II), e não por $A$. schaueriana, como proposto no padrão definido por Lugli (2004).

As parcelas I e II localizam-se na porção mais interna do bosque na margem esquerda do rio, ocorrendo em área classificada por Lugli (2004) como possuindo características similares as descritas anteriormente, mas na prática não foi isso o observado, pois estas parcelas apresentam dominância de $R$. mangle em densidade de indivíduos e possui características de vegetação de médio porte.

A representatividade de indivíduos mortos foi bastante baixa em todas as parcelas, refletindo em muitas ocasiões a mortalidade natural esperada para o bosque de mangue. Exceto na parcela IV que, como descrito anteriormente, há indivíduos cortados, o que resultou na maior taxa de mortalidade registrada, conforme pode ser observado na Tabela II e na Figura 3.

Na Figura 4 encontram-se descritos os dados de análise por classe de diâmetro para cada espécie presente nas parcelas considerando-se indivíduos vivos e mortos.

Destaca-se nas parcelas I e II (Figura 4) a dominância de indivíduos para $R$. mangle, principalmente nas classes de diâmetro entre 2,6-5,0 cm e nas classes de 2,6- 5,0 cm e 5,1-7,5 cm, respectivamente. Essa dominância é mais expressiva na parcela I, onde se registra também menor densidade das outras espécies. Conforme pode ser visualizado, a espécie pioneira nessas duas parcelas foi $A$. schaueriana, apresentando indivíduos nas classes de maior diâmetro, sendo, posteriormente, substituída por $R$. mangle e $L$. racemosa, esta em menor densidade que aquela. 
Nas parcelas III e IX há uma maior distribuição das espécies ao longo das diferentes classes de diâmetro (Figura 4), mas A. schaueriana se sobressai, sendo seguida por $R$. mangle. Já na parcela IV ocorre predomínio de $A$. schaueriana, que está sendo sucedida por $L$. racemosa, muito provavelmente em função do impacto causado pelo corte de árvores de
A. schaueriana de menor porte. É muito comum na área de estudo a utilização de troncos e galhos finos dessa espécie para a captura de caranguejos pela técnica da redinha. Esta atividade de coleta, utilizada por muitos pescadores, é altamente predatória, tanto para os caranguejos, pela sua captura, como para árvores, pelo seu corte.

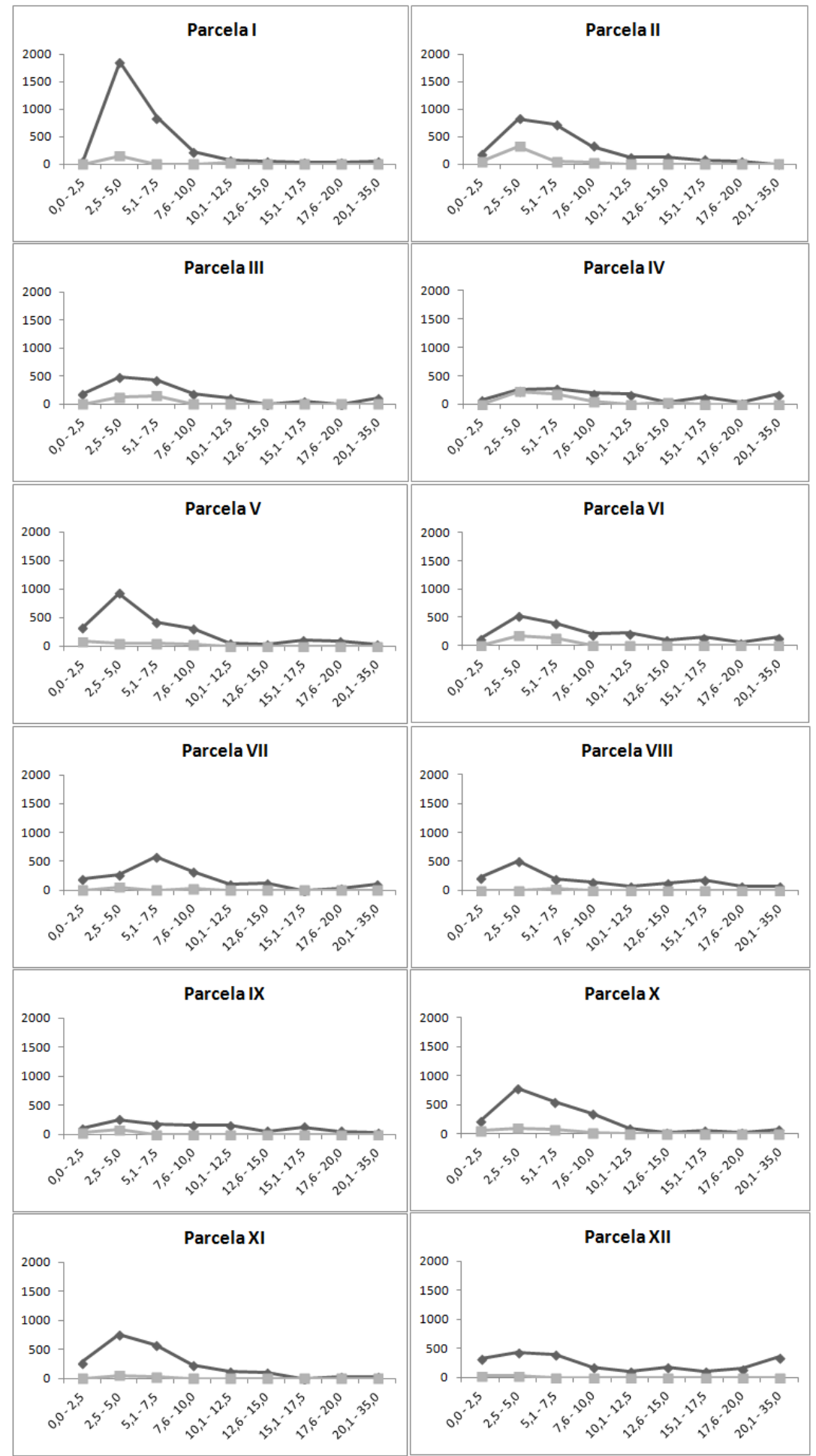

Figura 3 - Densidade indivíduos/hectare, vivos $(\bullet)$ e mortos $(\mathbf{\bullet})$, por classe de DAP. 
Em relação à parcela $V$ (Figura 4), observa-se aumento de densidade de $A$. schaueriana nas classes de diâmetro entre 2,6-5,0 cm e entre 7,6-10 cm. As demais espécies presentes também foram mais frequentes nessas classes de diâmetros inferiores a $10,0 \mathrm{~cm}$. A parcela VI registra maior ocorrência de $R$. mangle nas classes entre $10,1-12,5 \mathrm{~cm}$, com A. schaueriana distribuindo-se em todas as classes de diâmetro e apresentando maior densidade em diâmetros inferiores a $10,0 \mathrm{~cm}$. Similar a parcela VI, a VII apresenta maior frequência de ocorrência de $R$. mangle nas classes de diâmetro de $5,1 \mathrm{~cm}$ até $10 \mathrm{~cm}$.

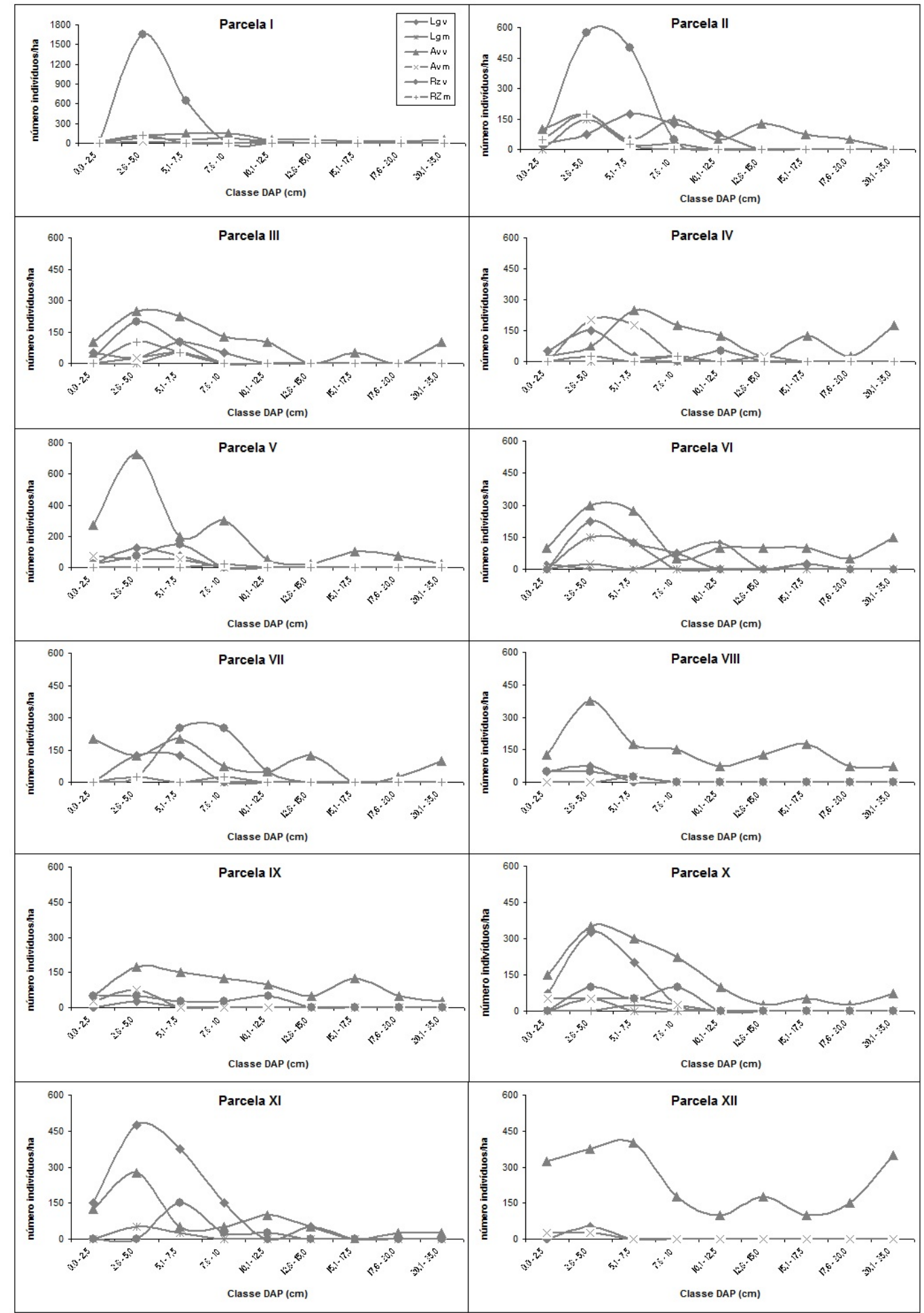

Figura 4 - Distribuição de indivíduos, por densidade (número indivíduos/ha) por classes de DAP nas parcelas, entre as espécies e suas condições de sobrevivência. 
Na parcela VIII há o domínio de A. schaueriana tendo presença quase constante ao longo das diferentes classes de diâmetro, registrando um pequeno aumento no intervalo de $2,6-5,0 \mathrm{~cm}$. Na parcela IX, A. schaueriana é dominante em todos os diâmetros observados, a parcela apresenta ainda registros discretos das outras duas espécies nas menores classes de diâmetro (Tabela II). Na parcela X, A. schaueriana ocorre principalmente na classe de diâmetro 5,1-7,5 $\mathrm{cm}$ sendo seguida por $L$. racemosa. Já na parcela $X \mathrm{X}$, o domínio em densidade de indivíduos é de $L$. racemosa, entre $5,1-7,5 \mathrm{~cm}$, declinando nas classes de diâmetros seguintes. $\mathrm{E}$, na XII há dominância de 99,65\% de densidade de indivíduos de $A$. schaueriana.

As parcelas III e IV estão localizadas no interior do bosque, próximas a um canal na margem esquerda do rio apresentando similaridade em relação à dominância de $A$. schaueriana e as demais espécies. As parcelas VII e VIII estão localizadas na margem direita do rio e possuem características estruturais semelhantes com domínio de $A$. schaueriana tanto em densidade de indivíduos como em área basal $\left(\mathrm{m}^{2} / \mathrm{ha}\right)$. As parcelas V, VI e X estão localizadas nas margens ao longo do rio ajustando entre si suas características. As parcelas XI e XII possuem algumas similaridades, mas diferem em termos de dominância, pois na parcela $X \mathrm{X}$, a espécie $L$. racemosa domina em densidade. As parcelas I, II e IX são as que possuem menos similaridade estrutural em relação às outras parcelas. Há variações de frequência de ocorrência das espécies em diversas classes de diâmetro, mas $A$. schaueriana foi presença constante em todas as classes, o que resultou a maior área basal em relação às outras duas espécies em todas as parcelas.

No presente estudo, $A$. schaueriana apresenta a maior área basal em todas as parcelas. Resultados similares foram obtidos por Souza et al. (1993) para o manguezal do Pontal da Daniela, onde L. racemosa foi à espécie dominante, mas $A$. schaueriana foi a espécie com maior altura e com maior área basal média.

A parcela I registrou o maior índice de densidade de indivíduos com menor DAP médio, devido à alta concentração desses mesmos indivíduos em classes de DAP entre 2,6-5,0 cm, sendo jovens e indicando um processo de colonização recente. A parcela IX possui a menor densidade de indivíduos por hectare e a parcela XI a menor área basal total com o terceiro menor valor de diâmetro médio. E a XII apresentou o maior DAP médio e área basal total por apresentar $22,7 \%$ dos seus indivíduos nas últimas classes diâmetro observadas neste estudo (entre 17,6-20,0 e 20,1-35,0 cm), levando a interpretação de que esta estrutura representa o bosque mais velho entre todas as parcelas analisadas.
No Rio Tavares, $R$. mangle domina em regiões de topografia mais baixa, em geral, caracterizada pela presença de microcanais, onde há grande circulação e alta frequência de inundação, como ocorre com a parcela I, e A. schaueriana se localiza, preferencialmente, em pequenas elevações topográficas, onde são submetidas a curtos períodos de submersão da maré, que no caso são as áreas onde esta espécie possui dominância em densidade de indivíduos. Este padrão também observado por Cunha-Lignon (2001).

Segundo Soares (1995), as diferentes espécies de vegetais de mangue estão distribuídas no manguezal em zonas, em relação à linha da água; dessa forma, temos geralmente o mangue vermelho (Rhizophora) ocupando os locais próximos ao mar, na margem de rios e locais lamosos, pelo fato de seus rizóforos permitirem sustentação no sedimento lodoso, e o mangue branco (Laguncularia) ocupa locais mais afastados dos rios e do mar, geralmente de topografia mais elevada, com sedimento mais seco e mais arenoso, os quais são protegidos das ondas e da força dos rios.

O modelo de desenvolvimento estrutural proposto por Jiménez et al. (1985) consiste nas etapas de período de colonização, desenvolvimento, maturidade e senescência. Considerando essas fases, procurou-se interpretar o estágio em que se encontram os bosques estudados. As parcelas I e II apresentam os valores mais altos de densidade de indivíduos com os menores diâmetros médios em relação ao restante das parcelas, permitindo enquadrá-las como parcelas em período de colonização.

As parcelas III, IV, V, VII, X e XI caracterizamse em período de desenvolvimento, pois os valores de densidade de indivíduos, área basal e altura são considerados como valores intermediários, podendo ainda haver um incremento desses valores. Observase nessas parcelas uma densidade bastante elevada (Figura 3) de indivíduos nas classes de diâmetro inferiores a $7,5 \mathrm{~cm}$.

Em relação aos bosques classificados como em período de maturidade incluem-se as parcelas VI, VIII, IX e XII. Na Figura 3 pode-se observar que esses bosques apresentam uma distribuição mais homogênea em todas as classes de diâmetro, registrando freqüência de indivíduos nas classes de diâmetro superiores a $15,0 \mathrm{~cm}$. Quanto à altura do dossel (Tabela IV) são os bosques que vão apresentar as maiores árvores e também os valores mais elevados de altura média.

Entretanto, apesar do enquadramento geral dos bosques estudados nas categorias propostas por Jiménez et al. (1985), esta avaliação é difícil de se realizar em bosques nos limites latitudinais de distribuição. Por exemplo, percebe-se pela análise das 
fotografias aéreas que as parcelas classificadas como em desenvolvimento registram essa colonização de forma muito lenta, ocorrendo há pelo menos dez anos.

As classificações propostas para as parcelas VI e XII podem ser comprovadas nas análises de Lugli (2004) onde na fotografia de 1938 já se pode visualizar a colonização desse bosque. Os dados obtidos neste estudo corroboram as interpretações realizadas pela autora tendo em vista que os dados de estrutura apresentam uma densidade alta de $A$. schaueriana com diâmetros ao redor de $35 \mathrm{~cm}$.

Pode-se afirmar que os estudos ecológicos necessitam de dados básicos sobre a estrutura do ecossistema e que as interpretações funcionais são processos mais lentos que respondem diretamente às influências ambientais e àquelas induzidas pelo homem em diferentes escalas temporais. Concluindo, pode-se dizer que:

- A espécie Avicennia schaueriana é presença constante em todas as classes de diâmetro, é dominante em área basal em todas as parcelas, sendo a espécie que colonizou primeiro os bosques de mangue estudados.

- Apesar das baixas temperaturas apresentadas no Estado de Santa Catarina, Rhizophora mangle é dominante em indivíduos em duas parcelas, devido aos bosques estarem localizados em regiões com presença de canais e variação da maré e em bosques onde se encontram protegidas por outras espécies.

- As parcelas I e II estão em Período de Colonização, as parcelas III, IV, V, VII, X e XI encontram-se em Período de Desenvolvimento, e as parcelas VI, VIII, IX e XII estão em Período de Maturidade.

\section{AGRADECIMENTOS}

As autoras agradecem a Universidade do Vale do Itajaí pelo apoio técnico e logístico durante o desenvolvimento deste estudo.

A primeira autora agradece a Universidade do Vale do Itajaí pela bolsa concedida para a realização do trabalho de conclusão de curso.

\section{REFERÊNCIAS BIBLIOGRÁFICAS}

Caruso, M. M. L. 1983. O Desmatamento da Ilha de Santa Catarina de 1500 aos dias atuais. Florianópolis: EDUFSC.

Cintrón, G. \& Schaeffer-Novelli, Y. 1983. Introducción a la ecologia del manglar. Oficina Regional de Ciencia y Tecnología de la UNESCO para America Latina y el Caribe. Montevidéu: ROSTLAC. 109p.
Cintrón, G. \& Schaeffer-Novelli, Y. 1985. Caracteristicas y desarrollo estructural de los manglares de Norte y Sur America. Ciênc. Interamer. 25(1-4): 4-15.

Cunha-Lignon, M. 2001. Dinâmica do manguezal no Sistema de Cananéia-Iguape, Estado de São Paulo - Brasil. Dissertação de Mestrado. Universidade de São Paulo - USP.

Jiménez, J. A. \& Soto, R. S. 1985. Patrones regionales en la estructura y composición florística de los manglares de la Costa Pacífica de Costa Rica. Rev. Biol. Trop. 33: 25-37.

Jiménez, J. A; Lugo, A. E. \& Cintrón, G. 1985. Tree mortality in mangrove forests. Biotropica 17(3): 177-185.

Lugli, D. O. 2004. Caracterização Ecológica do apicum do manguezal do Rio Tavares, Florianópolis, Santa Catarina. Dissertação de Mestrado. Universidade do Vale do Itajaí - UNIVALI.

Lugo, A. E. Avances y prioridades de investigation em manglares. In: Simposio Sobre Ecossistemas da Costa Sul e Sudeste Brasileira (Cananéia, 1987). Síntese dos conhecimentos. São Paulo, vol. 3, p. 59-76 (Publicação da ACIESP, n. 54).

Lugo, A. E. \& Snedaker, S. C. 1974. The ecology of mangroves. Annu. Rev. Ecol. Syst. 5:39-64.

Schaeffer-Novelli, Y. 1987. Manguezais brasileiros: região sudeste-sul. In: Anais do Simpósio sobre ecossistemas brasileiros da costa sul e sudeste: síntese dos conhecimentos, Cananéia, São Paulo. ACIESP, Cananéia, São Paulo. vol 1.78p.

Schaeffer-Novelli, Y. (coord). 1995. Manguezal: ecossistema entre a terra e o mar. Caribbean Ecological Research, São Paulo. 64p.

Schaeffer-Novelli, Y. \& Cintron, G. 1986. Guia para estudo de áreas de manguezal: estrutura, função e flora. Caribbean Ecological Research, São Paulo. 150p.

Schaeffer-Novelli, Y.; Coelho Jr, C. \& Tognella-DeRosa, M. 2001. Manguezais. Ática, São Paulo.

Sessegolo, G. C. 1997. Estrutura e Produção de Serapilheira do manguezal do Rio Baguaçu, Baía de Paranaguá - Paraná. Curitiba. Dissertação de Mestrado. Universidade Federal do Paraná - UFPR.

Snedaker, S. C. Mangrove species zonation: why? 1982. In: Sen, D.N. \& Rajpurohit, K.S. (eds.). Contributions to the ecology of halophytes: Tasks for vegetation science, vol. 2. Springer, Netherlands. 111-125 pp.

Soares, M. L. G. 1995. Zonação e as Marés. In: Shaeffer-Novelli, Y. (ed.) Manguezal: ecossistema entre a terra e o mar. 1. ed. Caribbean Ecological Research, São Paulo. 23-27 pp.

Soares, M. L. G. 1997. Estudo da biomassa aérea de manguezais do sudeste do Brasil- análise 
de modelos. Tese de Doutorado. Instituto Oceanográfico, Universidade de São Paulo - USP.

Soares, M. L. G.; Chaves, F. de O.; Corrêa, F. M. \& Silva Jr, C. M. G. da. 2003. Diversidade Estrutural de bosques de mangue e sua relação com distúrbios de origem antrópica: o caso da Baía de Guanabara (Rio de Janeiro). Anu. Inst. Geocienc. 26: 101-116.

Souza, M. L. D. R.; Falkenberg, D. B.; Amaral, L. G.; Fronza M.; Araujo, A. C. \& Sá, M. R. 1993. Vegetação do Pontal da Daniela, Florianópolis, SC, Brasil. II. Fitossociologia do manguezal. Insula 22: 107-142.

Souza, M. L. D. R.; Falkenberg, D. B.; Amaral, L. G.; \& Fronza, M. 1994. Fitossociologia do manguezal do Rio Tavares (Ilha de Santa
Catarina, Florianópolis, SC - Brasil). Insula 23: 99-119.

Souza-Sobrinho, R. J.; Bresolin, A. \& Klein, R. M. 1969. Os manguezais na llha de Santa Catarina. Insula 2: 1-21.

Tognella-De-Rosa, M. M. P. 2000. Manguezais Catarinenses, Baía da Babitonga e Rio Tavares: uma abordagem parcial dos atributos ecológicos e econômicos. Tese de Doutorado. Universidade de São Paulo - USP.

Tomlinson, P. B. 1986. The Botany of Mangrove. Cambridge Tropical Biology Series: University of Cambridge. 419p. 